\title{
PENERAPAN DIGITAL WATERMARK SEBAGAI VALIDASI KEABSAHAN GAMBAR DIGITAL DENGAN SKEMA BLIND WATERMARK
}

\author{
Adi Suheryadi ${ }^{1}$ \\ 1, Teknik Informaika - Politeknik Negeri Indramayu \\ ${ }^{1,}$ Indramayu, Indonesia \\ E-mail : adisuheryadi@polindra.ac.id ${ }^{1}$
}

\begin{abstract}
Abstrak
Digital watermarking merupakan bagian yang penting dalam perkembangan teknologi yang saat ini telah berkembang pada era digital. Era digital memberi motivasi untuk menyebarkan gambar di internet melalui website dengan skala besar. Disisi lain gambar digital merupakan objek yang sangat mudah untuk diubah atau dimanipulasi, dan bahkan disalin tanpa bertanggungjawab. Sebaliknya sangat sulit membuktikan gambar itu telah diubah dengan peralatan yang ada saat ini, selain itu sulit juga untuk dibuktikan kepemilikannya. Hal ini menjadi masalah penting, ketika gambar tersebut merupakan salah satu alat bukti untuk kasus hukum, pelaporan berita dan pengarsipan medis, dimana gambar tersebut haruslah dapat dipastikan bahwa gambar digital tersebut tidak mengalami perubahan ataupun manipulasi. Dalam penelitian ini kami menyajikan penerapan digital watermarking sebagai alat otentikasi dan validasi kepemilikan gambar digital. Sehingga gambar dapat dipastikan keabsahannya. Penelitian ini menerapkan skema blind watermark dengan menggunakan secret key yang disisipkan pada leastsignificant bits (LSB) gambar host secara invisible. Hasil yang didapatkan adalah gambar yang terwatermark mengalami penurunan kualitas yang kecil dengan nilai rata-rata PSNR dan MSE sekitar 34.08 dan 14.62 .
\end{abstract}

Kata Kunci: digital watermark, host, invisible watermark, secret key, least-significant bits(LSB).

\begin{abstract}
Digital watermarking is an important field of technological development that has now grown in the digital era. Digital era encourage the spread digital images on internet by the websites with a large scale. On the other hand, digital images are objects that are very easy to change or manipulate, and even copied irresponsibly. Meanwhile it is very difficult to prove the image has been changed by existing equipment at this time, and it is difficult to prove its ownership. This is an important issue, when the image is one of the evidences for legal cases, news reporting and medical filing, where the image must be ensured that the digital image is not subject to change or manipulation. In this paper, we present the application of digital watermarking to authentication and ownership validation of digital image so the image can be ascertained its validity. This research applies blind watermark scheme by using secret key that inserted at least-significant bits (LSB) of host image therefore the watermark is invisible watermark. The result of watermarked image has a small decrease in quality with the mean value of PSNR and MSE about 34.08 and 14.62 .
\end{abstract}

Keywords: digital watermark, host, invisible watermark, secret key, least-significant bits (LSB)

\section{PENDAHULUAN}

Digital watermarking adalah Teknik untuk menyisipkan informasi berupa watermark kedalam sebuah media digital seperti gambar, yang kemudian dapat diektrasi untuk berbagai tujuan diantaranya identifikasi atau otentikasi[1]. Tujuan utama dari digital watermarking adalah melindungi hak cipta. Digital watermarking akan menyisipkan sebuah informasi ke dalam sebuah set host-data dengan cara atau skema tertentu sehingga informasi tersebut tidak menggangu penggunaan host-data secara normal dengan tetap mempertahankan otentikasi host-data tersebut[2]. Klasifikasi skema watermark dapat ditentukan dari jenis informasi yang dibutuh oleh detector, yang mana dapat di klasifikasikan menjadi tiga skema klasifikasi yaitu skema non-blind, semi-blind, dan blind. Dari ketiga skema tersebut memiliki kebutuhan yang berbeda beda, pada skema non-blind membutuhkan host-data dan secret key untuk menyisipkan watermark. Skema semi-blind membutuhkan secret key dan watermark, sedangkan skema blind hanya membutuhkan secret key[3]. 
Salah satu yang menjadi tantangan besar dalam skema blind watermarking adalah memastikan watermark dapat terekstrak tanpa diberikan informasi dari berupa original host-nya.

Penyisipan watermark dalam suatu gamabar dilakukan dengan visible(terlihat) ataupun invisible(tidak terlihat) yang biasa disebut dengan visible watermarking dan invisible watermarking[4]. Invisible watermarking dalam beberapa dekade menjadi fokus penelitian.

Metode penyembunyian data untuk gambar dapat dikategorikan menjadi dua kategori yaitu bersifat spasialdomain dan domain frekuensi. Dalam domain spasial, pesan rahasia dalam hal ini watermark tertanam pada piksel gambar secara langsung. Metode yang paling umum adalah teknik histogram berbasis dan leastsignificant bits (LSB) dalam domain spasial.

Salah satu teknik spatial-domain telah dikenalkan dalam penyisipan watermark secara tesembunyi diantaranya datang dari Ping Wah Wang et.al [5], dimana beliau melakukan penelitian penyisipan watermark secara tersembunyi dengan menggunakan secret dan public key sebagai autentikasi dan verifikasi kepemilikan suatu karya digital berupa gambar. Dalam jurnal ini kami akan menerapkan konsep invisible watermarking dengan skema blind dan menggunakan secret key untuk memverifikasi karya digital berupa gambar. Jurnal ini disusun sebagai berikut. Pendahuluan diberikan Bagian I. Kajian terhadap pekerjaan terkait penelitian ada pada Bagian II. Bagian III menyajikan metode yang diusulkan. Hasil Eksperimental dibahas pada Bagian IV. Bagian V menjelaskan Kesimpulan.

\section{TINJAUAN PUSTAKA}

Invisible watermarking merupakan teknik penyisipan watermark secara digital dan tidak dapat dilihat scara visual. Dalam meyisipkan data secara invisible terdapat dua jenis teknik penyisipan yaitu spatial-domain dan frekuensi-domain. Teknik frekuensi domain akan memanfaatkan transformasi gambar pada domain frekuensi diantara metodenya adalah discrete cosine transformation (DCT)[8], discrete wavelet transformation (DWT) [9] dan lainnya. Jenis penyisipan watermark lainnya yaitu berdasar pada spatio-domain telah menjadi sangat poluler. Salah satu metode penyisipannya yaitu melalui least-significant bit (LSB) dan histogram-based.

Metode penyisipan invisible watermark dengan memanfaatkan least-significant bit (LSB) merupakan metode yang umum digunakan. Pada prinsipnya pesan yang disisipkan berada pada LSB host image atau cover. Guorong Xuan et al., [6] menggunakan trasformasi wavelet dan penyisipkan threshold untuk menysipkan data pada gambar digital. Dimana data dimasukkan ke dalam bit-plane least least (LSB) dari koefisien wavelet integer CDF frekuensi tinggi yang besarnya lebih kecil dari ambang batas yang telah ditentukan sebelumnya. Pada implemenatasinya modifikasi histogram diterapkan sebagai preprocessing untuk mencegah overflow/underflow. Selanjutnya evaluasi dari hasil percobaan menunjukkan bahwa skema ini lebih unggul dalam bentuk muatan yang lebih besar (pada PSNR yang sama) atau PSNR yang lebih tinggi (dengan muatan yang sama). Dalam penelitian ini masih membutuhkan cover/host untuk mengekstrak watermark.

Penelitian lain datang dari Ping Wah Wang et.al [5], wang menggunakan konsep LSB dengan mengenalkan dua skema yaitu menggunkan secret key dan public key. Dalam implementasinya wang berhasil menyisipkan watermark dengan tujuan otentikasi dan dan verifikasi kepemilikan suatu karya digital berupa gambar. Dalam penelitiannya Wang et.al menyisipkan 1-bit di LSB sehingga data dan cover yang digunakan relative kecil dalam level grayscale dan hitam-putih. Dalam penelitian ini sudah memperhatikan keamanan data/watermark yang digunakan dan menggunakan skema blind dalam penyisipan watermarking.

Fungsi hash berfungsi untuk mengkonversi input yang berupa string dengan ukuran yang panjang atau sembarang menuju ukuran panjang data yang fix(tetap), sebagaimana ditunjukan pada persamaan (1). Dalam penelitian ini menggunakan MD5 [7]. Panjang output dari MD5 adalah sekitar 128 bit,

$H(S)=\left(d_{1}, d_{2}, \ldots, d_{p}\right)$

Dimana $\mathrm{H}$ adalah fungsi hash, $\mathrm{S}$ merupakan string input, $\mathrm{d}$ merupakan output dan $\mathrm{p}$ adalah panjang hasil dari fungsi hash.

Dalam penelitian ini kami menyajikan alternaif implemetasi untuk mengamankan karya digital berupa gambar digital dengan menanamkan watermark sebagai otentikasi dan validasi serta keabsaan kepemilikan karya digital tersebut. Metode yang digunakan adalah penyisipan LSB sebagaimana yang dijelaskan Wang et.al[5]. Level gambar digital yang akan di ujikan pada level warna(RGB), Grayscale ataupun hitam-putih. Skema yang kami gunakan adalah skema blind dalam penyisipan watermarking, sehingga tidak memerlukan cover/host image pada saat proses ekstraksinya.

\section{III.METODE}

Pada bagian ini akan dijelaskan metode yang digunakan dalam penerapan digital watermarking yang diulas dalam jurnal ini. Proses dari digital watermarking terbagi menjadi dua bagian yaitu penyisipan watermarking dan ekstraksi watermarking. Penyisipan watermarking digunakan untuk menyisipkan watermark yang akan kita gunakan sebagai otentikasi dan validasi kepemilikan karya digital dalam hal ini adalah gambar. Sedangkan ekstraksi watermarking digunakan untuk penijauan otentikasi dan validasi kepemilikan karya digital tesebut.

\section{A. Penyisipan Watermark}

Pada gambar 1, ditampilkan blok diagram penyisipan watermark. Pada gambar tersebut terdapat delapan blok proses yaitu cek level gambar, meyamakan dimensi gambar, mengosongkan LSB cover, normalisasi watermark, pembentukan blok per blok, hashing proses, menggabungkan watermark dan hasil hash, dan terakhir penyisipan LSB. Input dari proses penyisipan watermark 
adalah $c v, w m$, dimana $c v$ adalah gambar cover atau host, dan $w m$ merupakan watermark atau logo.

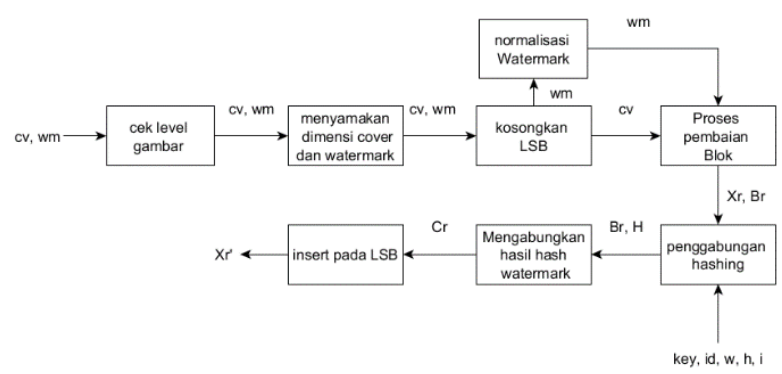

Gambar 1. Global Diagram Penyisipan Watermark

Blok cek level gambar digunakan untuk menentukan level gambar yang akan diproses level tersebut terbagi menjadi dua yaitu warna dan grayscale, sebagaimana terdapat pada persamaan (3). lv merupakan level gambar, $F_{\text {rgb }}$ jika ternyata cover berlevel warna dimana gambar akan memiliki 3 layer(lr) RGB, sedangkan $F_{\text {gry }}$ adalah jika level cover berupa grayscale memiliki 1 layer, persamaan (2). Setiap layer baik warna atau gray level terdiri dari 2 dimensi $(2 \mathrm{~d})$.

$l_{\text {rgb }}=3, l_{\text {gry }}<2$

$l v=\left\{\begin{array}{c}F_{r g b}, \quad s z(c v) \geq l r \\ F_{g r y}\end{array}\right.$

Pada level warna $\left(l_{r g b}\right)$ maka akan proses penyisipan mulai dari proses pembuatan blok dilakukan sebanyak 3 kali sesuai dengan layer yang dimiliki.

Blok proses selanjutnya adalah menyamkan dimensi gambar. Hal ini harus dilakukan karena metode yang digunakan adalah penyisipan LSB pada cover image sehingga perbedaan dimensi sangat berpengaruh. Dalam menyamakan dimensi antara cover dan watermark digunakan threshold static (th) hal ini disesuaikan dengan kebutuhan program tersebut. Dalam implementasi kami menggunakan dimensi gambar $250 \mathrm{x}$ 250, hal ini dipertimbangkan dari ideal logo yang digunakan. Hal ini ditunjukan pada persamaan (4). Proses selanjutnya adalah mengosongkan LSB cover, dimana tempat LSB yang dikosongkan tersebut akan digunakan tempat penyisipan watermark, ditunjukkan pada persamaan (5). $\operatorname{rem}(c v, \alpha)$ merupakan proses pencarian sisa bagi, sedangkan $\alpha$ merupakan koefisien untuk menentukan berapa sisa bagi yang akan diproses.

$c v\left(t h_{w} x t h_{w}\right), w m\left(t h_{w} x t h_{w}\right)$

$c v=c v-\operatorname{rem}(c v, \alpha), \alpha \geq 2$

Proses normalisasi watermark digunakan untuk mengkondisikan level pixel dari watermark sehingga tiap level pixelnya dapat disesuaikan sebagaimana kebutuhan. Proses normalisasi ditunjukan pada persamaan (6).

$w m=\frac{w m}{\beta}, \beta \in 2^{n}$
Dimana $\beta$ merupakan koefisiean yang digunakan untuk normalisasi. Panjang bit yang digunakan dapat dilihat dari hasil bagi maksimum $F$ dibagi dengan $\beta$, sebagaimana persamaan (7).

$n$ Bit $=\left|\frac{\max (F)}{\beta}\right|, \max (F) \geq 255$

Proses pembagian blok dilakukan tidak secara overlap, dimensi blok (thb) sebesar $25 \times 25$, proses pembagian blok ditunjukan pada persamaan (8) dan (9). Hasil dari pembagian blok tersebut akan digunakan untuk diproses selanjutnya.

$$
\begin{aligned}
& X r_{j, k}=\sum_{j=1, k=1}^{n, m} c v_{(j+t h b, k+t h b)}, j \geq 1, k \geq 1 \\
& B r_{j, k}=\sum_{j=1, k=1}^{n, m} w m_{(j+t h b, k+t h b)}, j \geq 1, k \geq 1 \\
& \operatorname{set} B x_{i}=\left[X r_{j, k}, \ldots, X r_{n, m}\right], i \geq 1 \\
& \operatorname{setB} w_{i}=\left[B r_{j, k}, \ldots, B r_{n, m}\right], i \geq 1
\end{aligned}
$$

Dimana $X r$ merupakan hasil dari pembentukan blok yang terbentuk dari gambar cover, sedangkan $\mathrm{Br}$ merupakan hasil dari pembentukan blok yang terbentuk dari gambar watermark. Sedangkan setBx dan setBm adalah kumpulan dari blok cover dan watermark. $i, j, k$ merupakan index dan $m, n$ adalah maksimal index.

Proses penggabungan (hashing proses) $H(X r, K e y, i d, w, h, i)$ digunakan untuk menyatukan semua informasi penting yang digunakan untuk otentikasi karya digital pada saat ekstraksi watermark. Data input yang dibutuhkan pada proses hashing ini diantaranya $X r$, key yang diperoleh dari password bersifat rahasia, id menggunakan NIM (Nomor Induk Mahasiswa) digunakan sebagai indetitas kepemilikan karya digital, w dan h merupakan lebar dan panjang yang merupakan dimensi gambar, serta $i$ merupakan index dari blok, persamaan (10) dan (11). Hashing proses menggunakan MD5[7]. Selanjutnya menggabungkan hasil hash dan watermark dengan menggunakan operasi XOR, hal ini ditunjukan dengan persamaan (12).

$C r=H(X r, K e y, i d, w, h, i) \otimes B r$

Dimana $\mathrm{Cr}$ merupakan hasil gabungan dari hasil hash $(H)$ dan blok dari watermark $(\mathrm{Br})$. Proses terakhir adalah penyisipan LSB, dalam proses ini LSB dari cover akan diisikan oleh $\mathrm{Cr}$. $\mathrm{Xr}$ ' merupakan hasil dari penyisipan $\mathrm{Cr}$ pada LSB Cover.

\section{B. Ekstraksi Watermark}

Proses ekstraksi watermark terdiri dari beberapa blok proses diantaranya adalah cek level gambar, proses pembentukan blok, ekstraksi LSB, hashing proses dan proses evaluasi menggunakan xor operasi. Blok diagaram dari proses ekstraksi watermark ditunjukan pada gambar (2).

Input dari proses ekstraksi watermark ini adalah gambar yang terwatermark. Pada proses pengecekan level gambar bertujuan untuk menentukan level baik itu 
warna ataupun grey level, sebagaimana yang ditunjukkan pada persamaan (2) dan (3). Proses pembentukan blok digunakan untuk membagi hasil blok menjadi beberapa bagian hal ini digunakan untuk mengevaluasi gambar yang terwatermark secara bertahap. Adapun proses pembentukan blok ditunjukkan pada persamaan (13), blok dibentuk dengan ukuran 25 x 25 (th). Dimana Yr adalah blok hasil dari pembagian gambar yang terwatermark $\left(X r^{\prime}\right)$.

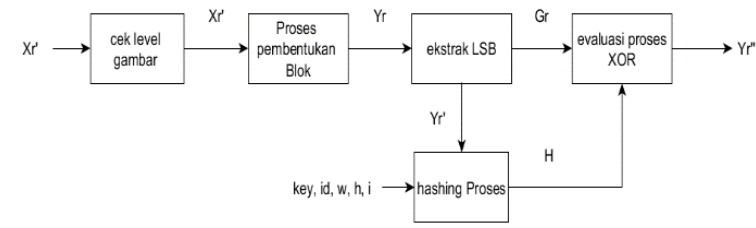

Gambar 2. Blok Diagram Ekstraksi Watermark

$Y r_{j, k}=\sum_{j=1, k=1}^{n, m} X r_{(j+t h, k+t h)}^{\prime}, j \geq 1, k \geq 1$

Proses selanjutnya adalah ekstraksi LSB, proses ini terdapat dua sub proses yaitu setting nol LSB pada gambar yang terwatermark sehingga akan menghasilkan $Y r^{\prime}$. Proses mengubah LSB menjadi nol ditunjukan pada persamaan (14).

$Y r^{\prime}=Y r-\operatorname{rem}(Y r, \alpha), \alpha \geq 2$

Sub proses yang kedua adalah ekstraksi LSB yang berfungsi untuk mendapatkan data LSB sesuai dengan koefisien $\alpha$. Hasil dari ekstraksi LSB adalah $G r$. Gr dan $Y r^{\prime}$ berdimensi sama dengan $Y r$. Proses ekstraksi ditunjukan pada persamaan (15).

$G r=Y r \wedge \theta, \theta \geq 1$

Dimana $\theta$ adalah koefisien yang akan menjadi operand untuk di operasikan terhadap $Y r$. Besaran $\theta$ disesuaikan dengan besar LSB yang akan digunakan. Pada penelitian ini $\theta$ sebesar 3 , penentuan $\theta$ ditunjukan pada persamaan (16)

$\theta=\sum_{p=0}^{n B I t-1} 2^{p}, p \geq 0$

Proses penggabungan (hashing proses) secara konsep sama seperti pada penyisipan watermark. Hashing proses $H\left(Y^{\prime}, K e y, i d, w, h, i\right)$ digunakan untuk menyatukan semua informasi penting yang digunakan untuk otentikasi karya digital pada saat ekstraksi watermark. Data input yang dibutuhkan pada proses hashing ini diantaranya $Y r^{\prime}$, key yang diperoleh dari password bersifat rahasia, id menggunakan NIM (Nomor Induk Mahasiswa) digunakan sebagai indetitas kepemilikan karya digital, w dan h merupakan lebar dan panjang yang merupakan dimensi gambar, serta $i$ merupakan index dari blok, persamaan (17).

$\operatorname{setB} y_{i}=\left[Y r_{j, k}^{\prime}, \ldots, Y r_{n, m}^{\prime}\right], i \geq 1$

Selanjutnya menggabungkan hasil hash dan watermark dengan menggunakan operasi XOR untuk mendapatkan watermark, yang merupakan hasil evaluasi proses. Hal ini ditunjukkan dengan persamaan (18).

$Y r^{\prime \prime}=H\left(Y r^{\prime}, K e y, i d, w, h, i\right) \otimes G r$

\section{HASIL DAN PEMBAHASAN}

Gambar yang digunakan dalam pengujian adalah gambar yang berwarna dan graylevel pada 2 gambar cover/host dan 4 gambar logo/watermark, ditunjukkan pada gambar (3) dan (4). Ukuran dari masing-masing gambar sebesar $250 \times 250$ pixel. Secret key berisi huruf, angka dan simbol dalam tipe data string, sedangkan id diambil dari NIM (Nomor Induk Mahasisa) yang bertipe data integer dengan panjang 8 sampai 10-digit. Parameter koefisien $\alpha=8, \beta=128$, dan $\theta=128$.

Performansi evaluasi kualitas watermark dan hasil gambar cover yang terwatermark diukur dengan menggunakan Peak Singal to Noise Ratio(PSNR), persamaan dari PSNR ditampilkan pada persaman (19). PSNR merupakan perbandingan antara nilai maksimum dari sinyal yang diukur dengan besarnya derau yang berpengaruh pada sinyal tersebut. PSNR diukur dalam satuan desibel. Sedangkan MSE(Mean Square Error) merupakan nilai error kuadrat rata-rata antara dua gambar, dalam hal ini adalah gambar cover dan gambar yang terwatermark. Peritungan matematis dari MSE ditunjukan pada persaman(20).

$$
\begin{aligned}
& P S N R=10 \log \frac{255^{2}}{M S E} \\
& M S E=\sum_{i=1, j=1}^{N-1, M-1} \frac{|C V(i, j)-X r \prime(i, j)|}{N x M}
\end{aligned}
$$

Dimana $\mathrm{N}$ dan $\mathrm{M}$ adalah dimensi dari gambar, sedangkan $c v$ adalah gambar cover dan $X r^{\prime}$ adalah gambar yang terwatermark dan $i, j$ merupakan index. Untuk gambar yang memiliki level warna (RGB) maka PSNR akan diproses sebanyak layer yang dimiliki, Hal ini ditunjukkan pada persamaan(21).

$P S N R_{r g b}=\frac{\sum_{i=1}^{l r} 10 \log \frac{255^{2}}{M S E_{i}}}{l r}$

Dimana $l r$ merupakan banyak layer yang dioperasikan.

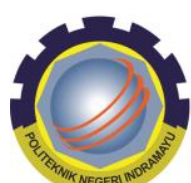

(a)

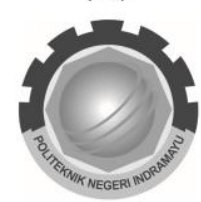

(e )

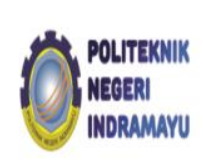

(b)

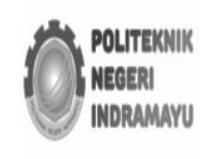

(f)

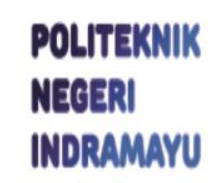

(c)

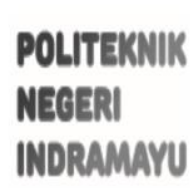

( g )

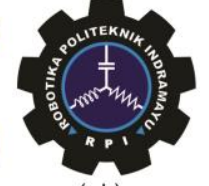

(d)

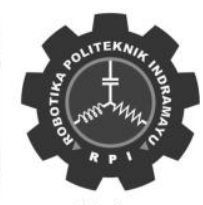

( h )
Gambar 3. Watermark: ( a ) logo1, ( b ) logo2, ( c ) logo3, ( d ) logo4, ( e ) logo5, ( f ) logo6, ( g ) logo7, ( h ) logo8.

Pada tabel diatas menunjukkan nilai PSNR rata-rata sebesar 34.08 dengan MSE rata sebesar 14.62. Nilai tersebut menujukkan kualitas gambar hasil watermark 
mengalami penurunan. Hal ini didapat dari perbandingan antara original cover/host dan gambar yang terwatermark.

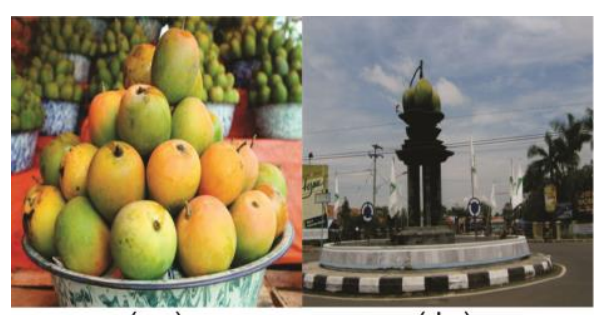

( a ) ( b )

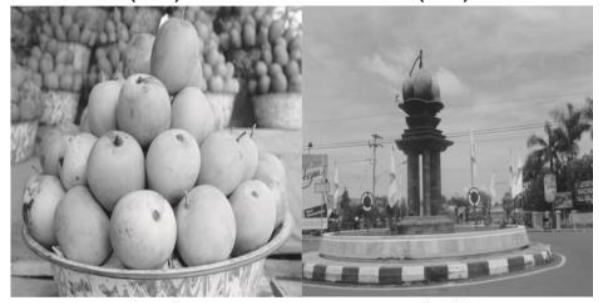

( c )

(d)

Gambar 4. Cover/Host: (a) cover1, (b) cover2, (c) cover3, (d) cover 4

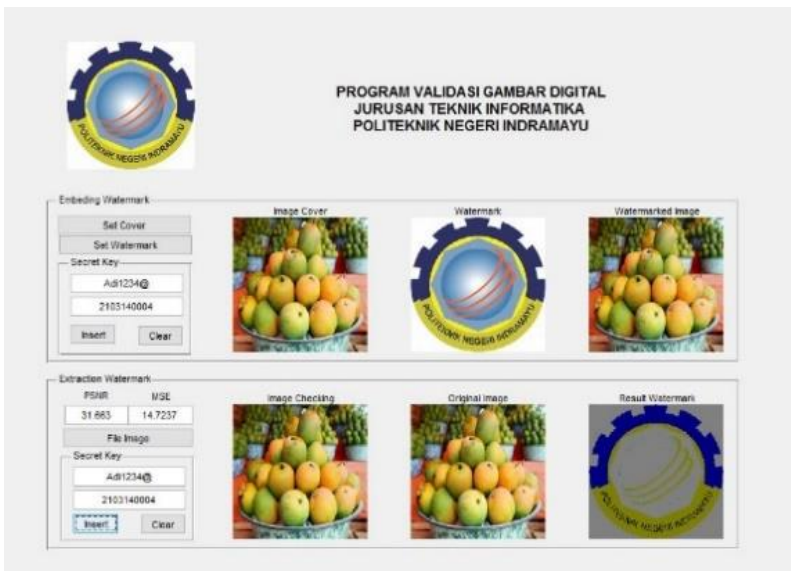

Gambar 5. Tampilan Aplikasi Validasi Gambar Digital

\begin{tabular}{|c|c|c|c|}
\hline \\
\hline Host & Watermark & PSNR & MSE \\
\hline \multirow[t]{4}{*}{ Cover1 } & logo1 & 31.67 & 14.70 \\
\hline & $\log _{0} 2$ & 31.62 & 14.86 \\
\hline & $\log _{0} 3$ & 31.63 & 14.84 \\
\hline & $\log _{0} 4$ & 31.77 & 14.36 \\
\hline \multirow[t]{4}{*}{ Cover2 } & $\log 01$ & 31.71 & 14.56 \\
\hline & $\log _{0} 2$ & 31.66 & 14.74 \\
\hline & logo 3 & 31.67 & 14.72 \\
\hline & $\log 04$ & 31.80 & 14.24 \\
\hline \multirow[t]{4}{*}{ Cover3 } & $\log _{0} 5$ & 36.45 & 14.68 \\
\hline & $\log 06$ & 36.40 & 14.86 \\
\hline & $\log 07$ & 36.44 & 14.72 \\
\hline & $\log 08$ & 36.55 & 14.32 \\
\hline \multirow[t]{4}{*}{ Cover4 } & $\log 05$ & 36.47 & 14.58 \\
\hline & logo6 & 36.42 & 14.76 \\
\hline & $\log 07$ & 36.46 & 14.65 \\
\hline & $\log _{0} 8$ & 36.56 & 14.29 \\
\hline \multicolumn{2}{|c|}{ Rata-rata } & 34.08 & 14.62 \\
\hline
\end{tabular}

\section{PENUTUP}

\section{Kesimpulan}

Dalam penelitian ini kami menajikan penerapan digital watermarking sebagai validasi keabsahan file multimedia (gambar digital) dengan menggunakan skema blind watermark. Proses penyisipan watermark dilakukan dengan metode LSB yang mana panjang digit LSB yang kami gunakan adalah sebanyak 2-bit LSB. Pada penelitian ini menggunakan dua level gambar yaitu gambar warna dan gambar berlevel grayscale. Hal ini menjadi suatu alternatif penyisipan invisible watermark pada gambar dengan level warna secara spasial dengan mempertimbangkan beberapa koefisien sebagaimana telah dipaparkan pada bagian II. Hasil dari penelitian ini menunjukkan kualitas gambar yang terwatermark mengalami penurunan namun tidak signifikan, ditunjukan dengan nilai PSNR dan MSE relatif rendah. Keberhasilan melakukan ekstraksi watermark pada gambar, memudahkan proses otentikasi dan validasi kepemilikan gambar digital dengan diwakili oleh key yang berupa password dan id yang merupakan nomor unik dari pemilik gambar. Meskipun demikian hasil eksraksi gambar masih mengalami penurunan kualitas yang signifikan.

\section{Saran}

Kami menyarankan sebagai pengembangan penelitian selanjutnya yaitu memperbaiki kualitas hasil ekstraksi watermark yang mana dapat dimulai dengan peningkatan jumlah bit LSB dan memperhatikan proses normaslisasi watermark pada proses penyisipan dan ekstraski watermark. Selain itu dapat dikombinasikan dengan metode-metode yang berdomain frekuensi. Selanjutnya meningkatkan fungsional dan penanganan file multimedia yang dapat di operasikan.

\section{DAFTAR PUSTAKA}

[1] S. Lagzian, M. Soryani, M. Fathy, "A New Robust Watermarking Scheme Based on RDWT-SVD", International Journal of Intelligent Information Processing, vol. 2, no. 1, pp. 22-29, 2011.

[2] F. Hartung, M. Kutter, "Multimedia watermarking techniques", Proc. IEEE, vol. 87, pp. 1079-1107, July 1999.

[3] A. Sverdlov, S. Dexter, A.M. Eskicioglu, "Robust DCT-SVD Domain Image Watermarking For Copyright Protection: Embedding Data In All Frequencies", Proceedings of the 13th European Signal Processing Conference (EUSIPCO2005), Antalya, Turkey, September 2005.

[4] V.M. Potdar, S. Han, E. Chang, "A Survey of Digital Image Watermarking Techniques", Proc. IEEE International Conference on Industrial Informatics, Aug. 2005.

[5] Secret and Public Key Image Watermarking Schemes for Image Authentication and Ownership Verification.

[6] Guorong Xuan, Yun Q. Shi \& Chengyun Yang "Lossless Data Hiding Using Integer Wavelet Transform and Threshold Embedding Technique" 07803-9332-5/05/\$20.00 @2005 IEEE. 
[7] R. L. Rivest, "The MD5 message digest algorithm," Tech. Rep., 1992.

[8] N. Divecha and D. N. N. Jani, "Implementation and performance analysis of DCT-DWT-SVD based watermarking algorithms for color images," International Conference on Intelligent Systems and Signal Processing (ISSP), pp. 204-208, 2013.

[9] J. Guru, H. Dhamecha and B. Patel, "Fusion of DWT and SVD digital watermarking Techniques for robustness," International Journal of Advanced Research in Computer Science and Software Engineering, vol. 4, no. 9, pp. 791-797, 2014. 